\title{
Prevention and treatment of strokes associated with carotid artery stenosis: a research priority
}

Stroke is a leading cause of death and disability worldwide. Each year about 1,400,000 strokes occur in Europe (1) and 800,000 strokes in the United States (2), causing more than 1.2 million deaths annually $(1,2)$. About a third of these (34\%) are ischemic strokes following thromboembolism from an ipsilateral internal carotid artery stenosis (3). However, about two-thirds of these patients will not have a $>50 \%$ carotid stenosis, thus leaving about $10-15 \%$ of all strokes being due to thromboembolism from a previously asymptomatic 50-99\% carotid artery stenosis (ACS) (3).

Despite substantial improvements in medical therapy, the number of strokes has not decreased significantly over time. An earlier report showed that in 1998 approximately 770,000 Americans suffered a stroke (4). The latest data from the United States nearly 20 years later ( $\mathrm{n}=795,000$ strokes) shows that this number has not been reduced dramatically (2), although it should be considered that the population has grown in number during this period. As a result of the increase in life expectancy, there has been a shift of strokes to the more elderly patients (5), i.e., the number of strokes is more or less the same, but they tend to occur in more elderly patients. In other words, medical therapy delays but does not necessarily prevent their occurrence. Due to the huge costs associated with stroke [e.g., \$34 billion/year in the United States (2); €38 billion/year in Europe (1)], attempts should be made to reduce the financial, as well as the social burden of the disease.

As a result of the increasing prevalence of obesity worldwide, type 2 diabetes mellitus has become the pandemic of the $21^{\text {st }}$ century (6). Diabetes is associated with an increased risk of ACS (7) and also increases the risk of ischemic stroke by more than 2-fold (8). Therefore, the implementation of timely vascular disease prevention strategies in diabetic patients is crucial and should be expected to reduce the incidence of strokes associated with ACS.

The optimal management of patients with ACS has been the subject of extensive debates. The need to introduce and establish appropriate stroke risk stratification models for ACS patients is essential to identify those patients who may benefit from a prophylactic intervention $(9,10)$. Carotid artery stenting (CAS) has emerged as a less invasive alternative to carotid endarterectomy (CEA) for the management of ACS (11). As CAS is almost always performed under local anesthesia, it avoids the disadvantages of surgical procedures (e.g., general anesthesia, longer postoperative hospitalization, increase in complications such as myocardial infarction, etc.). A disadvantage of CAS in symptomatic patients is the higher perioperative stroke and death rates in these patients compared with CEA $(12,13)$. The introduction of new generation stents and novel techniques (e.g., transcervical access with blood flow reversal) appear promising $(14,15)$. However, the efficacy of these novel techniques needs to be verified in randomized controlled trials and large observational studies before any solid conclusions can be drawn.

Several "gray" areas regarding the management of carotid stenosis are currently under investigation, such as the optimal management of patients with carotid near-occlusion. Some guidelines recommend conservative treatment in patients with nearocclusion (16), whereas a 2015 meta-analysis demonstrated that an intervention is probably indicated in these patients (17). Other controversial topics include the optimal management of ACS, the treatment-of-choice of carotid restenosis following an intervention, as well as the optimal timing of intervention for patients with recently symptomatic carotid stenosis.

One subgroup of ACS patients considered at high risk for future stroke is those with silent cerebral ischemic lesions on brain CT scans (1). The Asymptomatic Carotid Stenosis and Risk of Stroke (ACSRS) Study showed that patients with 60-99\% ACS who demonstrated silent cerebral infarcts had a 3-fold higher stroke risk compared with individuals without embolic infarcts (18). Several other clinical and imaging features are associated with an increased risk of late stroke in patients with high-grade ACS and have therefore been proposed to be able to identify the high-risk asymptomatic carotid patients. Examples of such features include increased plaque area on computerized plaque analysis, intraplaque hemorrhage on magnetic resonance imaging, impaired cerebrovascular reserve and spontaneous embolization on transcranial Doppler (1). Further research on these fields is warranted to improve patient selection and stroke risk classification models.

The prevention and optimal management of ischemic strokes associated with ACS is of interest for several medical specialties, including neurologists, stroke physicians, vascular surgeons, interventional radiologists, angiologists and others. The aim of the current series is to provide an outline of the various controversial issues and techniques, as well as to present 
the strengths and limitations of the various proposed diagnostic imaging modalities that need to be addressed by future research, thus optimizing stroke outcomes for patients.

\section{Acknowledgments}

Funding: None.

\section{Footnote}

Provenance and Peer Review: This article was commissioned by the editorial office, Annals of Translational Medicine for the series "Carotid Artery Stenosis and Stroke: Prevention and Treatment Part I". The article did not undergo external peer review.

Conflicts of Interest: The author has completed the ICMJE uniform disclosure form (available at http://dx.doi.org/10.21037/ atm-2020-cass-25). The series "Carotid Artery Stenosis and Stroke: Prevention and Treatment Part I" was commissioned by the editorial office without any funding or sponsorship. KIP served as the unpaid Guest Editor of the series. The author has no other conflicts of interest to declare.

Ethical Statement: The author is accountable for all aspects of the work in ensuring that questions related to the accuracy or integrity of any part of the work are appropriately investigated and resolved.

Open Access Statement: This is an Open Access article distributed in accordance with the Creative Commons AttributionNonCommercial-NoDerivs 4.0 International License (CC BY-NC-ND 4.0), which permits the non-commercial replication and distribution of the article with the strict proviso that no changes or edits are made and the original work is properly cited (including links to both the formal publication through the relevant DOI and the license). See: https://creativecommons.org/ licenses/by-nc-nd/4.0/.

\section{References}

1. Naylor AR, Ricco JB, de Borst GJ, et al. Editor's choice - management of atherosclerotic carotid and vertebral artery disease: 2017 Clinical Practice Guidelines of the European Society for Vascular Surgery (ESVS). Eur J Vasc Endovasc Surg 2018;55:3-81.

2. Centers for Disease Control and Prevention. Stroke Facts and Statistics. Available online: https://www.cdc.gov/stroke/facts.htm. Accessed on May 15, 2020.

3. Naylor AR. Why is the management of asymptomatic carotid disease so controversial? Surgeon 2015;13:34-43.

4. Leary MC, Saver JL. Annual incidence of first silent stroke in the United States: a preliminary estimate. Cerebrovasc Dis 2003;16:280-5.

5. van Koeverden ID, van Haelst STW, Haitjema S, et al. Time-dependent trends in cardiovascular adverse events during followup after carotid or iliofemoral endarterectomy. Br J Surg 2017;104:1477-85.

6. Ginter E, Simko V. Type 2 diabetes mellitus, pandemic in 21st century. Adv Exp Med Biol 2012;771:42-50.

7. de Weerd M, Greving JP, Hedblad B, et al. Prediction of asymptomatic carotid artery stenosis in the general population: identification of high-risk groups. Stroke 2014;45:2366-71.

8. Banerjee C, Moon YP, Paik MC, et al. Duration of diabetes and risk of ischemic stroke: the Northern Manhattan Study. Stroke 2012;43:1212-7.

9. Paraskevas KI, Ricco JB. The imperative need to identify stroke risk stratification models for patients with asymptomatic carotid artery stenosis. J Vasc Surg 2018;68:1277-8.

10. Paraskevas KI, Veith FJ, Spence JD. How to identify which patients with asymptomatic carotid stenosis could benefit from endarterectomy or stenting. Stroke Vasc Neurol 2018;3:92-100.

11. Habersberger J, Brott TG, Roubin GS. Carotid artery stenting: a clinical update. Curr Opin Cardiol 2012;27:565-71.

12. Paraskevas KI, Veith FJ, Riles TS, et al. Is carotid artery stenting a fair alternative to carotid endarterectomy for symptomatic 
carotid artery stenosis? A commentary on the AHA/ASA guidelines. J Vasc Surg 2011;54:541-3; discussion 543.

13. Paraskevas KI, Kalmykov EL, Naylor AR. Stroke/death rates following carotid artery stenting and carotid endarterectomy in contemporary administrative dataset registries: a systematic review. Eur J Vasc Endovasc Surg 2016;51:3-12.

14. Paraskevas KI, Veith FJ. Transcervical access, reversal of flow and mesh-covered stents: New options in the armamentarium of carotid artery stenting. World J Cardiol 2017;9:416-21.

15. Paraskevas KI, Veith FJ, Parodi JC. Commentary: transcervical carotid artery stenting (CAS) with flow reversal: a promising technique for the reduction of strokes associated with CAS. J Endovasc Ther 2016;23:255-7.

16. Aboyans V, Ricco JB, Bartelink MEL, et al. Editor's Choice - 2017 ESC Guidelines on the Diagnosis and Treatment of Peripheral Arterial Diseases, in collaboration with the European Society for Vascular Surgery (ESVS). Eur J Vasc Endovasc Surg 2018;55:305-68.

17. Mylonas SN, Antonopoulos CN, Moulakakis KG, et al. Management of Patients with Internal Carotid Artery Near-total Occlusion: An Updated Meta-analysis. Ann Vasc Surg 2015;29:1664-72.

18. Kakkos SK, Sabetai M, Tegos T, et al. Silent embolic infarcts on computed tomography brain scans and risk of ipsilateral hemispheric events in patients with asymptomatic internal carotid artery stenosis. J Vasc Surg 2009;49:902-9.

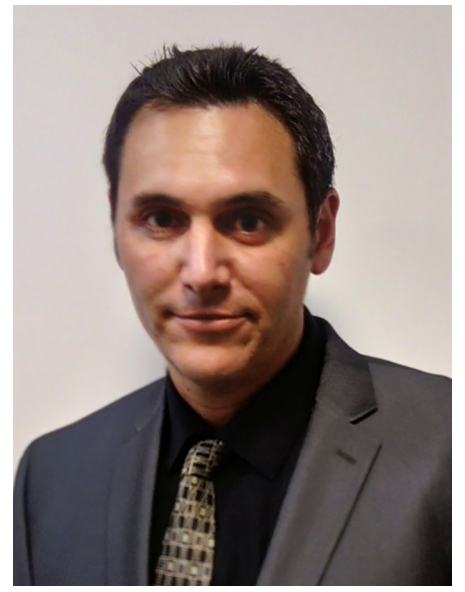

Kosmas I. Paraskevas

Kosmas I. Paraskevas, MD, PhD

Department of General and Vascular Surgery, Central Clinic of Athens, 24, Alex. Papagou Street, N. Iraklio 14122, Athens, Greece.

(Email: paraskevask@hotmail.com)

Submitted May 28, 2020. Accepted for publication Jun 23, 2020.

doi: $10.21037 / \mathrm{atm}-2020$-cass-25

View this article at: http://dx.doi.org/10.21037/atm-2020-cass-25

Cite this article as: Paraskevas KI. Prevention and treatment of strokes associated with carotid artery stenosis: a research priority. Ann Transl Med 2020;8(19):1260. doi: 10.21037/atm2020-cass-25 